\title{
Self-reported responsiveness to direct-to-consumer drug advertising and medication use: results of a national survey
}

\author{
Nicholas J Dieringer', Lisa Kukkamma², Grant W Somes ${ }^{3}$ and Ronald I Shorr ${ }^{1,2,4^{*}}$
}

\begin{abstract}
Background: Direct-to-consumer (DTC) marketing of pharmaceuticals is controversial, yet effective. Little is known relating patterns of medication use to patient responsiveness to DTC.

Methods: We conducted a secondary analysis of data collected in national telephone survey on knowledge of and attitudes toward DTC advertisements. The survey of 1081 U.S. adults (response rate $=65 \%$ ) was conducted by the Food and Drug Administration (FDA). Responsiveness to DTC was defined as an affirmative response to the item: "Has an advertisement for a prescription drug ever caused you to ask a doctor about a medical condition or illness of your own that you had not talked to a doctor about before?" Patients reported number of prescription and over-the-counter (OTC) medicines taken as well as demographic and personal health information.
\end{abstract}

Results: Of 771 respondents who met study criteria, 195 (25\%) were responsive to DTC. Only 7\% respondents taking no prescription were responsive, whereas $45 \%$ of respondents taking 5 or more prescription medications were responsive. This trend remained significant ( $p$ trend .0009) even when controlling for age, gender, race, educational attainment, income, self-reported health status, and whether respondents "liked" DTC advertising. There was no relationship between the number of OTC medications taken and the propensity to discuss health-related problems in response to DTC advertisements $(p=.4)$.

Conclusion: There is a strong cross-sectional relationship between the number of prescription, but not OTC, drugs used and responsiveness to DTC advertising. Although this relationship could be explained by physician compliance with patient requests for medications, it is also plausible that DTC advertisements have a particular appeal to patients prone to taking multiple medications. Outpatients motivated to discuss medical conditions based on their exposure to DTC advertising may require a careful medication history to evaluate for therapeutic duplication or overmedication.

Keywords: Advertising, medication use, consumerism, prescription medication, non-prescription medication

\section{Background}

Considerable controversy surrounds the practice of directto-consumer (DTC) marketing of pharmaceuticals. While some argue that DTC advertising serves as an educational resource for patients,[1] others say that DTC advertising contributes to the medicalization of trivial ailments, and leads to overuse and misuse of pharmaceuticals[2]. Since initially allowed by the Food and Drug Administration in

\footnotetext{
* Correspondence: rshorr@ufl.edu

'Department of Medical Education, Methodist Healthcare, 1265 Union

Avenue, Memphis, TN 38104, USA

Full list of author information is available at the end of the article
}

1985,[3] spending on DTC advertising grew steadily over the following decade. DTC advertising spending accelerated rapidly after 1997, when the Food and Drug Administration provided draft guidance which described how sponsors could disseminate information on drugs and biological products using radio and television $[4,5]$. Pharmaceutical industry expenditures for DTC advertising increased 330\% between 1996 and 2005. In 2005, \$4.2 billion was spent on DTC advertising, which accounted for $14 \%$ of all promotional spending for prescription drugs[6]. Expenditures have decreased (in absolute terms) since 2007 following a peak of $\$ 5.4$ billion in 2006 [7].

\section{(Ciomed Central}


Although it is difficult to find data on the effectiveness of DTC advertising for individual drugs, $10-35 \%$ of survey respondents say they have discussed medical conditions or medications with their physicians as a result of DTC advertising [8-10]. Furthermore, patients who specifically request medications during an office visit are much more likely to receive them than those who do not[9,11-13].

While much has been written regarding consumer and physician attitudes toward DTC advertising, less is known relating patient characteristics, notably medication use, and responsiveness to DTC advertising. One survey found that responders to DTC advertising were more likely to be nonwhite, have lower educational attainment and lower income,[10] whereas Bell found that women, as well as persons with a positive attitude towards DTC advertising, in poorer self-reported health, and with better self-reported insurance coverage of medications were more likely to respond to DTC advertising[9]. This survey also found that persons using prescription drugs at the time of the interview were more likely to be influenced by DTC advertising. To further investigate the relationship between self-reported medication use and responsiveness to DTC advertising, we conducted a secondary analysis of data obtained in an FDA survey of exposure to, perceptions of, and attitudes toward DTC advertising.

\section{Methods}

\section{Data Source}

The data come from a national telephone survey of adults in the U.S., investigating the demographic characteristics and attitudinal effects of DTC prescription drug advertising of survey respondents[5]. The survey was conducted by a professional research firm for the Food and Drug Administration between April and July 1999 to examine attitudes and influence of DTC advertising of prescription drugs upon the healthcare experience. The target population for the survey was English speaking consumers aged 18 or older.

Respondents were contacted using random digit dialing methodology and several steps were taken to optimize the response rate. Interviews were scheduled for varying times of the day in an effort to locate potential respondents at a convenient time. Respondents were allowed to schedule "call back" appointments to complete the survey at a more convenient time. Unlimited call backs (more than 40) were utilized for phone numbers that did not initially yield a respondent contact. Respondents who initially refused to participate, or terminated the interview before completion were contacted by a mailed follow-up letter as well as two follow-up telephone solicitations.

\section{Study Population}

1081 persons responded to the survey representing a response rate of $65 \%$ (eligible respondents who completed survey plus ineligible respondents divided by the total contacted minus bad telephone numbers). From these, 310 persons who had not been exposed to DTC prescription drug marketing in the three months prior to the survey, and therefore did not answer the question of interest, were excluded. Table 1 describes those persons excluded from the analysis. Thus our study population included 771 persons.

\section{Main Measures}

"Responsiveness to DTC drug marketing" was defined as an affirmative response to the survey item: "Has an advertisement for a prescription drug ever caused you to ask your doctor about a medical condition or illness of your own that you had not talked to a doctor about

Table 1 Characteristics of Respondents Not Exposed to DTCA, Excluded From Study

\begin{tabular}{|c|c|}
\hline Characteristic & Prevalence \\
\hline \multicolumn{2}{|l|}{ Age } \\
\hline Less than 65 years & 72.0 \\
\hline 65 years or older & 28.0 \\
\hline \multicolumn{2}{|l|}{ Gender } \\
\hline Male & 35.2 \\
\hline Female & 64.8 \\
\hline \multicolumn{2}{|l|}{ Race } \\
\hline White & 66.5 \\
\hline Non-white & 33.5 \\
\hline \multicolumn{2}{|l|}{ Marital Status } \\
\hline Married & 49.7 \\
\hline Single, widowed, divorced, other & 50.3 \\
\hline \multicolumn{2}{|l|}{ Educational Attainment } \\
\hline College graduate or higher & 23.2 \\
\hline Some college or less & 76.8 \\
\hline \multicolumn{2}{|l|}{ Annual Income } \\
\hline Less than $\$ 35,000$ & 57.9 \\
\hline$\$ 35,000$ or more & 42.1 \\
\hline \multicolumn{2}{|l|}{ Time since last visit to physician } \\
\hline Within one month & 40.7 \\
\hline More than one month & 59.3 \\
\hline \multicolumn{2}{|l|}{ Self-reported health } \\
\hline Excellent & 17.8 \\
\hline Very Good & 29.1 \\
\hline Good & 27.2 \\
\hline Fair & 18.1 \\
\hline Poor & 7.8 \\
\hline Mean \# of Rx drugs in past 6 months & 2 (S.D. 1.6) \\
\hline Mean \# of OTC drugs in past 6 months & $1.2($ S.D. 1.2) \\
\hline
\end{tabular}


before?" Prescription and OTC drug use was determined using the self-reported number of prescription drugs, and OTC drugs used within the six month period prior to the survey.

\section{Covariates}

Covariates were also determined from the survey. These included gender, race, income, marital status, date of last physician visit, self-reported health, self-reported knowledge about health and medications, and attitude toward DTC drug advertisements. Self-reported health was assessed with a single item using a five point scale ranging from 1 ("excellent" health) to 5 ("poor" health). Self-reported knowledge about health and medications was assessed with a single item using a four point scale ranging from 1 ("extremely" knowledgeable) to 5 ("not at all" knowledgeable). Attitude toward DTC drug advertisements was assessed with a single item asking how much the respondent "liked" DTC advertising with responses on a five point scale ranging from 1 ("strongly agree") to 5 ("strongly disagree").

\section{Statistical Analysis}

We used T-test and chi-square tests for univariate analyses. For multivariate analysis, we used logistic regression controlling for covariates. These covariates included age, gender, race, educational attainment, marital status, income, self-reported health status, selfreported knowledge of medicines and health, and attitude toward DTC advertising. We performed all analyses using SAS version 9.1 (SAS Institute Inc, Cary, $\mathrm{NC}$ ). All p-values were 2 -sided and $\alpha$ was set at .05 .

\section{Results}

\section{Characteristics of the Study Sample}

The average respondent's age was (mean \pm s.d.) $46.1 \pm$ 15.7 years, $64 \%$ were female, and $81 \%$ were white. Fortytwo percent had completed at least a college degree and $57 \%$ were married at time of interview. On average, respondents had encountered $2.4 \pm 1.3$ modes of delivery of DTC prescription drug advertising (e.g. magazines, television, newspaper, etc.) in the three months prior to the interview. Respondents' mean score for how much they "liked seeing" these advertisements was $2.7 \pm$ 1.4. The mean response for respondents' self-reported knowledge of medications and health matters in general was $2.6 \pm 0.7$. Similarly, mean response for respondents' self-reported health status was $2.4 \pm 1.1$ see Table 2 .

\section{Relationship between Respondent Characteristics and Responsiveness to DTC Marketing}

Overall, 195 (25.3\%) respondents answered affirmatively to our variable of interest, indicating that they had initiated discussion of a medical problem with their physician based on DTC advertising. Compared to respondents who denied discussing medical problems with their physicians based on DTC advertising, respondents who used DTC advertising as a foundation for discussing a new health problem with their physician were older, possessed less educational attainment, and "liked" seeing DTC prescription drug advertisements. Gender, race, marital status, self-reported health status, self-reported knowledge about health and medications, and income were not significantly associated with the primary endpoint (see Table 2).

\section{Relationship between Self-Reported Prescription Medication Use and Responsiveness to DTC Marketing}

The mean number of prescription drugs used in the six months prior to the survey was $2.4 \pm 1.6$. Of 108 persons using no prescription medications, 9 (8.3\%) were responsive to DTC advertisements. Of 131 persons using five or more prescription medicines, 50 (38.1\%) were responsive to DTC advertisements. There was a strong trend $(\mathrm{p}<.0001)$ in the relationship between number of prescription medications used and responsiveness to DTC advertisements. This association remained highly significant $(\mathrm{p}=.0009)$ even when controlling for demographics, self-reported health status, educational attainment, race, marital status, self-reported knowledge of medications and health, number of OTC medications used, income, and attitude toward DTC advertisements see Figure 1.

\section{Relationship between Self-Reported OTC Medication Use and Responsiveness to DTC Marketing}

The average number OTC drugs used in the six months prior to the survey was $1.8 \pm 1.4$. Of 136 persons using no OTC medications, 44 (32.3\%) were responsive to DTC. Of 61 persons using five or more OTC medicines, $20(32.7 \%)$ were responsive to DTC. There was no linear trend in either univariate $(\mathrm{p}=.54$. $)$ or multivariate $(\mathrm{p}=$ .76) relationship between number of OTC medications used and responsiveness to DTC see Figure 2.

\section{Discussion}

Our data indicate that a cross-sectional relationship exists between number of prescription drugs used and "responsiveness" to DTC advertising. This strong linear relationship remains even when controlling for demographic and socioeconomic variables and self-reported health. Overall, $25.3 \%$ of respondents were motivated by DTC advertising to initiate discussion regarding new health problems. Among respondents taking no prescription medications, fewer than $10 \%$ were motivated by DTC advertising. Conversely, among respondents taking five or more prescription medicines, nearly $40 \%$ were motivated. 
Table 2 Sample Characteristics by Responsiveness to DTC Advertising

\begin{tabular}{|c|c|c|c|}
\hline Covariate & Prevalence & $\begin{array}{l}\text { Proportion responsive to } \\
\text { DTC advertising }\end{array}$ & $\begin{array}{c}\text { Multivariate association with responsiveness to DTC } \\
\text { advertising (OR, } 95 \% \mathrm{Cl})\end{array}$ \\
\hline \multicolumn{4}{|l|}{ Age } \\
\hline Less than 65 years & 85.9 & 23.2 & $2.5(1.5-4.1)$ \\
\hline 65 years or older & 14.1 & 37.6 & \\
\hline \multicolumn{4}{|l|}{ Gender } \\
\hline Male & 36.1 & 22.2 & $1.0(.7-1.5)$ \\
\hline Female & 63.8 & 27.3 & \\
\hline \multicolumn{4}{|l|}{ Race } \\
\hline White & 82.6 & 24.5 & $.7(.4-1.0)$ \\
\hline Non-white & 17.4 & 31.1 & \\
\hline \multicolumn{4}{|l|}{ Marital Status } \\
\hline Married & 57.5 & 25.5 & $1.1(.7-1.6)$ \\
\hline Single, widowed, divorced, other & 42.1 & 25.0 & \\
\hline \multicolumn{4}{|l|}{ Educational Attainment } \\
\hline College graduate or higher & 57.8 & 28.9 & $.7(.4-1.0)$ \\
\hline Some college or less & 42.1 & 20.3 & \\
\hline \multicolumn{4}{|l|}{ Annual Income } \\
\hline Less than $\$ 35,000$ & 48.6 & 25.8 & $1.2(.8-1.9)$ \\
\hline$\$ 35,000$ or more & 51.3 & 24.8 & \\
\hline \multicolumn{4}{|l|}{ Self-reported health } \\
\hline Excellent & 23.2 & 13.4 & $1.1(1.0-1.4)$ \\
\hline Very Good & 41.4 & 25.1 & \\
\hline Good & 22.1 & 32.9 & \\
\hline Fair & 11.9 & 28.5 & \\
\hline Poor & 4.4 & 44.1 & \\
\hline \multicolumn{4}{|l|}{ Time since last visit to physician } \\
\hline Within one month & 59.6 & 27.4 & $.9(.6-1.4)$ \\
\hline More than one month & 40.4 & 22.2 & \\
\hline \multicolumn{4}{|c|}{$\begin{array}{l}\text { Self-reported knowledge about health } \\
\text { and medications }\end{array}$} \\
\hline Extremely knowledgeable & 8.8 & 22.1 & $1.0(.8-1.3)$ \\
\hline Very knowledgeable & 30.0 & 25.5 & \\
\hline Somewhat knowledgeable & 58.2 & 25.4 & \\
\hline Not at all & 3.0 & 26.1 & \\
\hline \multicolumn{4}{|l|}{$\begin{array}{l}\text { Like seeing advertisements for } \\
\text { prescription drugs }\end{array}$} \\
\hline Strongly agree & 20.4 & 41.6 & $1.4(1.2-1.6)$ \\
\hline Agree somewhat & 31.0 & 24.4 & \\
\hline Neither agree or disagree & 20.8 & 20.7 & \\
\hline Disagree & 10.9 & 18.1 & \\
\hline Strongly disagree & 16.9 & 15.5 & \\
\hline
\end{tabular}

$\mathrm{n}=771$

In 2002, the Government Accountability Office has identified 13 surveys, primarily for lay publications, which attempted to assess consumer behavior related DTC advertising[8]. Since that time several additional surveys have been published in the medical and scientific literature[10,14-16]. In these studies, the proportion of respondents who reported being influenced by DTC advertising to seek medical care ranged from 10.5 to $35 \%$. Although there is some variation in how each survey defines responsiveness to DTC advertising, our finding that $25 \%$ of respondents had discussed a new medical condition with a physician based on DTC advertising is generally consistent with others.

Our results confirm those of previous studies, [10,17] which identify older age, lower educational attainment and a positive attitude towards DTC advertising as factors associated with responsiveness to DTC advertising $[9,10]$. In contrast to other studies, $[14,18]$ we did not 


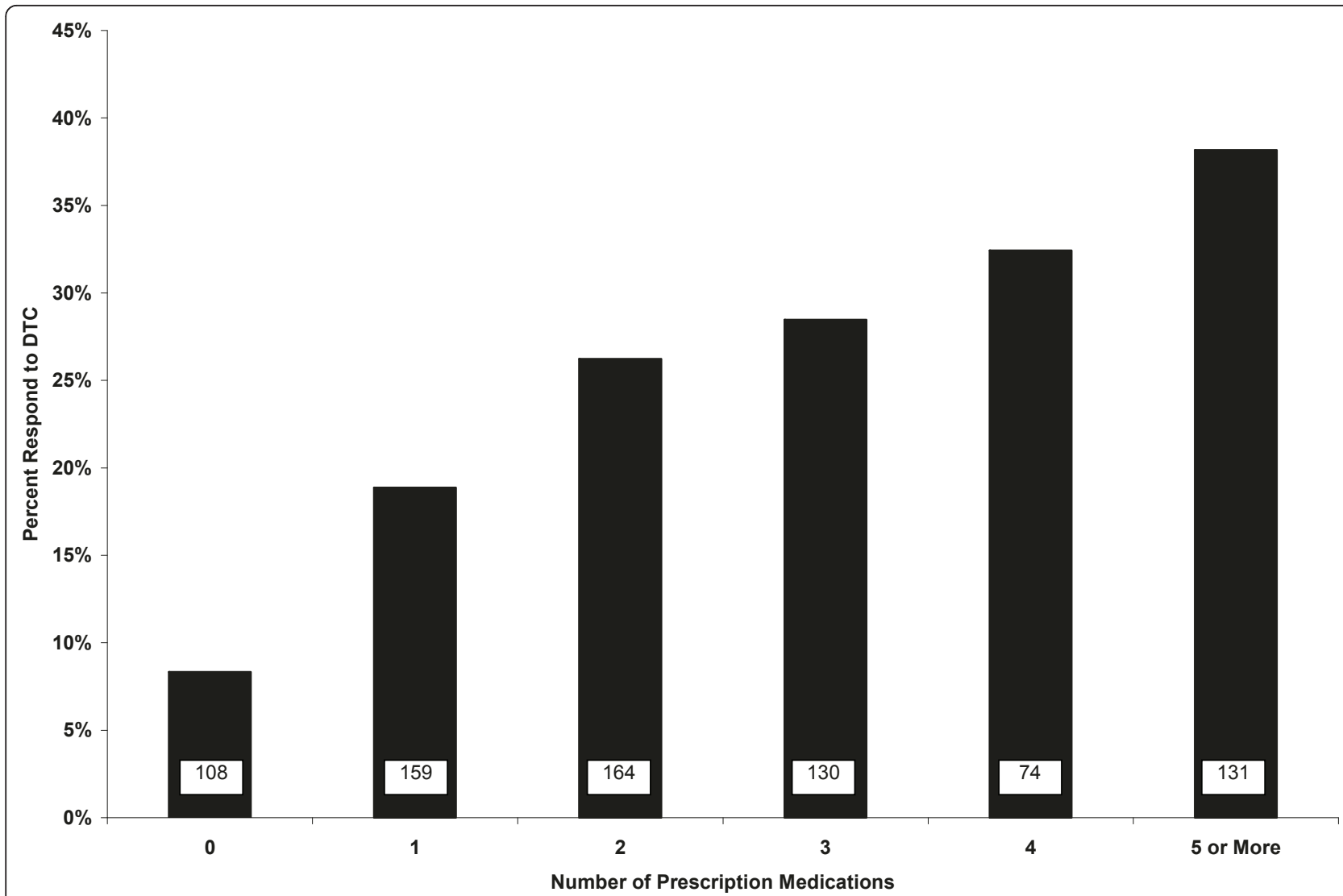

Figure 1 Proportion of respondents who were responsive to direct-to-consumer (DTC) advertising, by number of self-reported prescription medications used in six months prior to study. The number of respondents in each category is embedded in the bars.

find an association between ethnicity, income or selfreported health status and DTCA.

We found that a cross-sectional relationship exists between responsiveness to DTC and self-reported use of prescription, but not OTC, drugs. Because there was a trend towards poorer self-reported health and responsiveness to DTC, is plausible that users of prescription medications represent a sicker population, and one that may be more attuned to the messages conveyed in DTC advertising. Alternatively, because DTC advertising largely focuses on prescription medications, persons who are responsive to DTC may have approached their prescribers based on information in DTC, resulting in more prescription, rather than OTC, use. Bell and colleagues found that current users of prescription drugs were more likely to be influenced by DTC advertising,[9] but did not quantify the number of prescriptions, and limited their sample to one county in California.

Our investigation confirms results of a smaller study of Minnesotans by Schommer et al. [15] that found prescription medication use to be statistically greater in respondents who were responsive to DTC advertising than those who were not. Similar to our results, no significant difference was found in the number of OTC medications used by responsive versus unresponsive patients.

The main strength of our study is that the source of data comes from a large nationally representative sample with a high response rate. Furthermore, unlike some other studies, OTC as well as prescription drug use was ascertained. Our study has several limitations. First, these data were collected in 1999. Penetration and awareness of DTC advertising, as well as types of media outlets (e.g. internet), have increased considerably in subsequent years. Despite this, however, we are encouraged by similarities in regard to attitudinal, socioeconomic and demographic predictors of susceptibility to DTC advertising demonstrated in more recent surveys, $[14,15]$ and likewise feel that the relationship between number of prescription drugs used and susceptibility to DTC advertising should be no less true today. Second, this is a secondary analysis of FDA data originally collected to investigate attitudinal and demographic effects toward DTC advertising; thus, rigorous ascertainment of medication use was not included. Although the selfreported medication use measure is a limitation, it has 


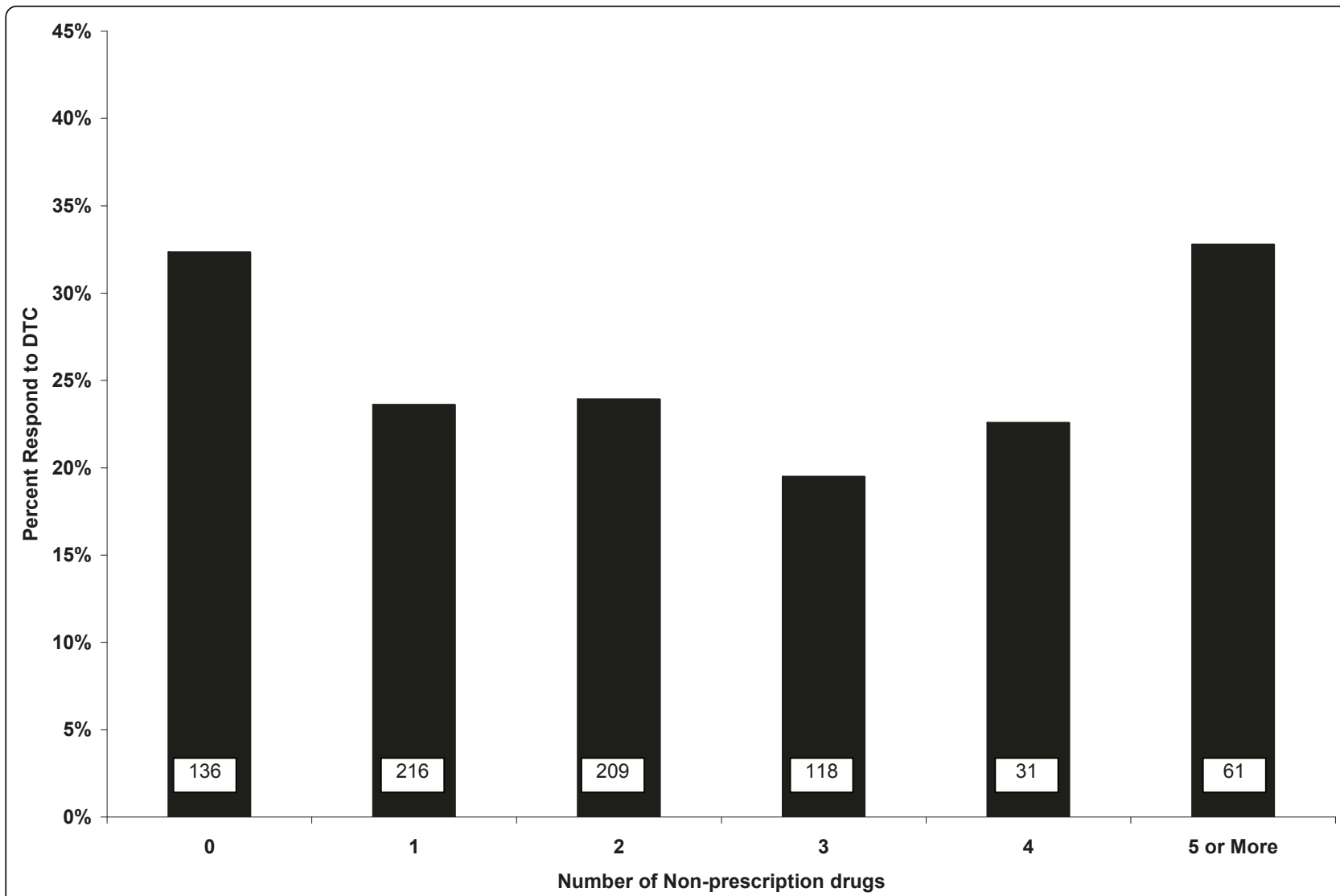

Figure 2 Proportion of respondents who were responsive to direct-to-consumer (DTC) advertising, by number of self-reported nonprescription medications used in six months prior to study. The number of respondents in each category is embedded in the bars.

been used in a previous survey of DTC advertising,[15] and has been found to be congruent with pharmacy prescription data[19,20].

The cross-sectional nature of this study does not allow for unequivocal statements regarding the direction of causality. Although this relationship could be explained by physician compliance with patient requests for medications, it is also plausible that DTC advertisements have a particular appeal to patients prone to taking multiple medications. Finally, the main measure in this study specifically asks about initiating discussion with a physician about a new medical problem and thus may not have captured those patients who use DTC advertisements to prompt discussion of previously discussed problems, or those patients who may have discontinued a medication due to information contained in DTC advertisements.

\section{Conclusion}

There is a strong cross-sectional relationship between the number of prescription, but not OTC, drugs used and responsiveness to DTC advertising. Although this relationship could be explained by physician compliance with patient requests for medications, it is also plausible that DTC advertisements have a particular appeal to patients prone to taking multiple medications. Outpatients motivated to discuss medical conditions based on their exposure to DTC advertising may require a careful medication history to evaluate for therapeutic duplication or overmedication.

Further research needs to be performed to understand this population's eagerness to utilize prescription drugs and to determine if this eagerness transcends to utilization of other health care resources. Clearly, these DTC advertisements are powerful motivators. Perhaps they could be used to enhance evidence-based prescribing and advance public health.

\section{Acknowledgements}

This research was supported in part by the $21^{\text {st }}$ Century Scholars Program, The Urban Child Institute, Memphis, TN. The authors would like to thank Kathryn J. Aikin, Ph.D. Division of Drug Marketing, Advertising and Communications, Center for Drug Evaluation and Research, Food and Drug Administration for her helpful comments; and Kathryn M. Jemmott, M.A., MSW for her editorial assistance. Material in this paper presented as: Dieringer NJ, Shorr Rl. Effectiveness of direct to consumer advertising among the already medicated. (Poster Presentation at the 27th Annual Meeting of the Society for General Internal Medicine, Chicago, IL 5/04) 


\section{Author details}

'Department of Medical Education, Methodist Healthcare, 1265 Union Avenue, Memphis, TN 38104, USA. ${ }^{2}$ GRECC (182) NF/SG Veterans Health System 1601 SW Archer Road, Gainesville, FL 32608, USA. ${ }^{3}$ Department of Preventive Medicine, University of Tennessee Health Science Center, Memphis, TN 3810, USA. ${ }^{4}$ Department of Aging and Geriatric Research, University of Florida, Gainesville, FL, USA.

\section{Authors' contributions}

ND and RS conceived of the study, participated in its design, performed statistical analyses, interpreted the data, and helped draft and revise the manuscript. LC and GS participated in the analysis and interpretation of the data and helped draft and revise the manuscript. All authors read and approved the final manuscript.

\section{Competing interests}

The authors declare that they have no competing interests.

Received: 1 January 2011 Accepted: 23 September 2011 Published: 23 September 2011

\section{References}

1. Holmer AF: Direct-to-consumer prescription drug advertising builds bridges between patients and physicians. JAMA 1999, 281:380-382.

2. Rados C: Truth in Advertising: Rx Drug Ads Come of Age. FDA Consum 2004, 38(4):20-27.

3. Wilkes MS, Bell RA, Kravitz RL: Direct-to-consumer prescription drug advertising: trends, impact, and implications. Health Aff (Millwood) 2000, 19:110-128.

4. Rosenthal MB, Berndt ER, Donohue JM, Frank RG, Epstein AM: Promotion of prescription drugs to consumers. N Engl J Med 2002, 346:498-505.

5. Aikin KJ, Swasy JL, Braman JC: Patient and Physician Attitudes and Behaviors Associated With DTC Promotion of Prescription Drugs Summary of FDA Survey Research Results: Final Report. US Department of Health and Human Services Food and Drug Administration Center for Drug Evaluation and Research [http://www.fda.gov/downloads/Drugs/ ScienceResearch/ResearchAreas/

DrugMarketingAdvertisingandCommunicationsResearch/UCM152860.pdf], Published November 19, 2004. Accessed August 7, 2011.

6. Donohue JM, Cevasco M, Rosenthal MB: A decade of direct-to-consumer advertising of prescription drugs. N Engl I Med 2007, 357:673-681.

7. Thomaselli R: DTC spending falls for second consecutive year Advertising Age.[http://adage.com/article/news/dtc-spending-falls-consecutive-year/ 132499/, Published November 12, 2008. Accessed August 7, 2011.

8. Prescription drugs: FDA oversight of direct-to-consumer advertising has limitations. (GAO-03-177). Washington, D.C.: United States General Accounting Office; 2002.

9. Bell RA, Kravitz RL, Wilkes MS: Direct-to-consumer prescription drug advertising and the public. J Gen Intern Med 1999, 14:651-657.

10. Robinson AR, Hohmann KB, Rifkin JI, Topp D, Gilroy CM, Pickard JA, Anderson RJ: Direct-to-consumer pharmaceutical advertising: physician and public opinion and potential effects on the physician-patient relationship. Arch Intern Med 2004, 164:427-432.

11. Understanding the Effects of Direct-to-Consumer Prescription Drug Advertising. Henry J Kaiser Family Foundation [http://www.kff.org/rxdrugs/ 3197-index.cfm.], Published November 29, 2001. Accessed August 7, 2011.

12. Kravitz RL, Epstein RM, Feldman MD, Franz CE, Azari R, Wilkes MS, Hinton L, Franks P: Influence of patients' requests for direct-to-consumer advertised antidepressants: a randomized controlled trial. JAMA 2005, 293:1995-2002

13. Mintzes B, Barer ML, Kravitz RL, Kazanjian A, Bassett K, Lexchin J, Evans RG, Pan R, Marion SA: Influence of direct to consumer pharmaceutical advertising and patients' requests on prescribing decisions: two site cross sectional survey. BMJ 2002, 324:278-279.

14. Murray E, Lo B, Pollack L, Donelan K, Lee K: Direct-to-consumer advertising: public perceptions of its effects on health behaviors, health care, and the doctor-patient relationship. J Am Board Fam Pract 2004, 17:6-18.

15. Schommer JC, Singh RL, Hansen RA: Distinguishing characteristics of patients who seek more information or request a prescription in response to direct-to-consumer advertisements. Res Social Adm Pharm 2005, 1:231-250.

16. Khanfar N, Loudon D, Sircar-Ramsewak F: FDA direct-to-consumer advertising for prescription drugs: what are consumer preferences and response tendencies? Health Mark Q 2007, 24:77-91.

17. Weissman JS, Blumenthal D, Silk AJ, Newman M, Zapert K, Leitman R, Feibelmann S: Physicians report on patient encounters involving directto-consumer advertising. Health Aff (Millwood) 2004, Suppl Web Exclusives: W4-33.

18. Lee D, Begley CE: Racial and ethnic disparities in response to direct-toconsumer advertising. Am J Health Syst Pharm 2010, 67:1185-1190.

19. Curtis JR, Westfall AO, Allison J, Freeman A, Kovac SH, Saag KG: Agreement and validity of pharmacy data versus self-report for use of osteoporosis medications among chronic glucocorticoid users. Pharmacoepidemiol Drug Saf 2006, 15:710-718.

20. Caskie GI, Willis SL: Congruence of self-reported medications with pharmacy prescription records in low-income older adults. Gerontologist 2004, 44:176-185.

\section{Pre-publication history}

The pre-publication history for this paper can be accessed here: http://www.biomedcentral.com/1472-6963/11/232/prepub

\section{doi:10.1186/1472-6963-11-232}

Cite this article as: Dieringer et al:: Self-reported responsiveness to direct-to-consumer drug advertising and medication use: results of a national survey. BMC Health Services Research 2011 11:232.

\section{Submit your next manuscript to BioMed Central and take full advantage of:}

- Convenient online submission

- Thorough peer review

- No space constraints or color figure charges

- Immediate publication on acceptance

- Inclusion in PubMed, CAS, Scopus and Google Scholar

- Research which is freely available for redistribution

Submit your manuscript a www.biomedcentral.com/submit
Ciomed Central 